\title{
Investigating the factors affecting participation in clinical decision- making from viewpoint of physicians and nurses of educational hospitals of Qazvin
}

\author{
Niloofar Movafegh ${ }^{1}$, Shahlla Mohamadzade Zarankesh ${ }^{2}$, Mohammad Kazem Naeeni ${ }^{3}$ \\ ${ }^{1}$ MSC of Nursing, Tehran Medical Sciences, Islamic Azad University, Tehran, Iran \\ ${ }^{2}$ Faculty Member, PhD Student of Higher Education Management, Tehran Medical Sciences, Islamic Azad University, \\ Tehran, Iran \\ ${ }^{3}$ Faculty Member, PhD of Statistics, Tehran Medical Sciences, Islamic Azad University, Tehran, Iran
}

\begin{abstract}
Background: Inter-professionals collaboration between nurses and physicians are essential for improving the quality of health care services. The purpose of this study was to determine the factors influencing participation in clinical decision making from the viewpoint of nurses and doctors.

Materials and methods: In this cross-sectional study, 140 nurses and 100 Physicians in educational Hospitals to Qazvin University of Medical Sciences were evaluated using two separate researcher-made questionnaires (doctor and nurse versions) in four levels of individual, social, clinical and organizational factors.

Results: The attitude of physicians to participation in clinical decision making in individual (23.07\%), social $(18.46 \%)$, organizational $(18.07 \%)$, and clinical $(16.92 \%)$ factors was good. Nurses had good attitude to individual $(34.61 \%)$ and organizational $(34.99 \%)$ factors, and medium attitude to social $(28.45 \%)$ and clinical $(26.15 \%)$ regarding participation in clinical decision making. The attitude of physicians to factors affecting participation was better than nurses $(\mathrm{p}<0.001)$.

Conclusion: Based on the results of this study, the use of proper management practices and the provision of workshops for the implementation of physician- nurses' contributions is necessary.

Keywords: Clinical decision making, Factors affecting participation, Attitude, Physician, Nurse.
\end{abstract}

Cited as: Movafegh N 'Mohamadzade Sh، Naeeni M. Investigating the factors affecting participation in clinical decision-making from viewpoint of physicians and nacres of educational Hospital of Qazvin. Medical Science Journal of Islamic Azad University, Tehran Medical Branch 2019; 29(3): 249-257.

Correspondence to: Shahlla Mohammadzadeh Zarankesh

Tel: +989122759896

E-mail: shmohammadzadeh@yahoo.com

ORCID ID: 0000-0002-2383-218x

Received: 23 Oct 2018; Accepted: 24 Dec 2018 
مجله علوم يزشكى دانشعاه آزاد اسلامى

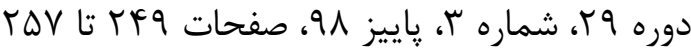

\title{
بررسى عوامل موثر بر مشاركت در تصميه گيرى بالينى از ديدگاه يرستاران و
} يزشكان بيمارستانهاى آموزشى وابسته به دانشعاه علوم يزشكى شهرستان قزوين

\author{
نيلوفر موافق'، شهلا محمد زاده زرنكش؟؛ كاظم نايينى
}

'كارشناسى ارشد يرستارى، دانشكده يرستارى و مامائى، علوم يزشكى تهران ، دانشكاه آزاداسلامى ، تهران ، ايران

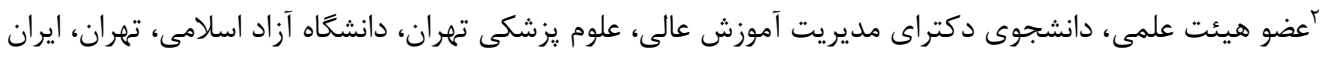

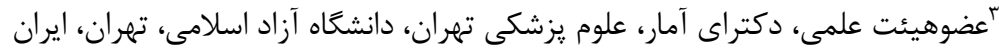

سابقه و هدف: مشاركت و همكارى بين حرفهاى بين برستاران و برشكان براى /رتقا برايندهاى بيمار وكيفيت /رائه خدمات بهد/شتى ضرورى

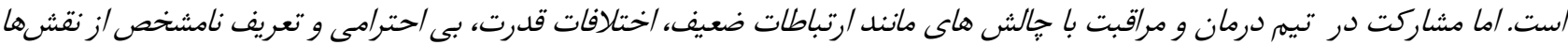

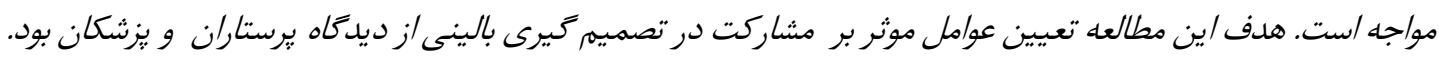

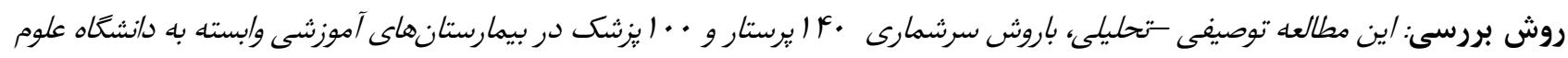

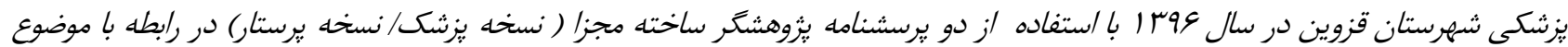

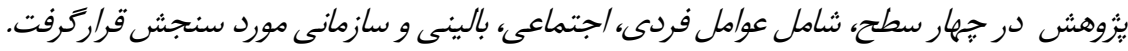

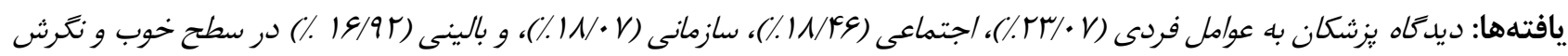

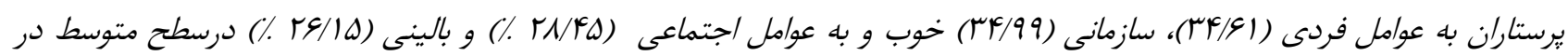

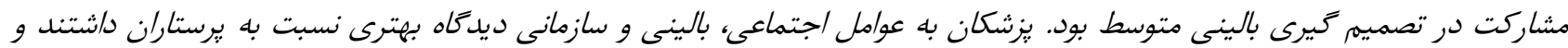

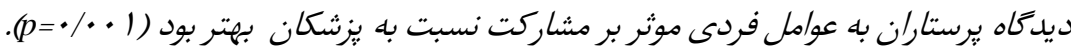

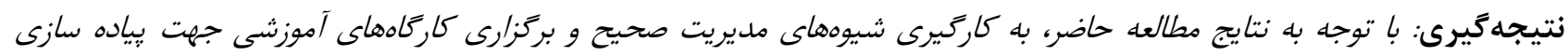

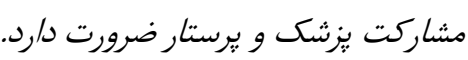

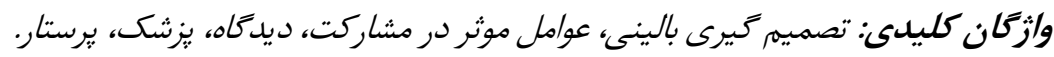

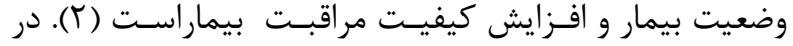

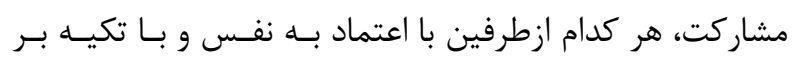
دانش و اطلاعات خود و با احترام متقابل و با توجه به امكانسات

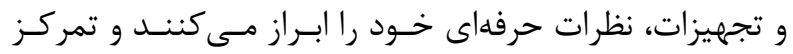

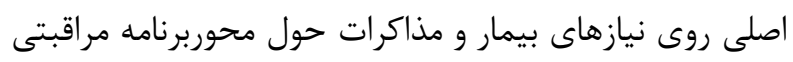

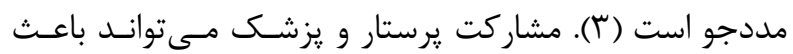

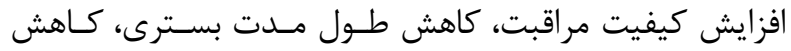

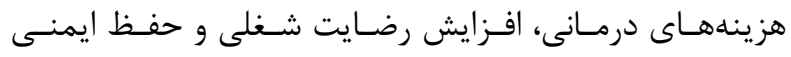

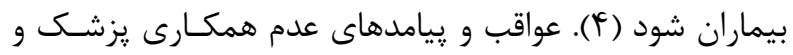

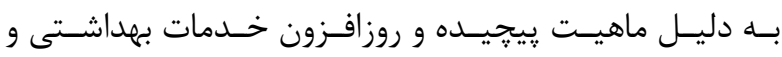

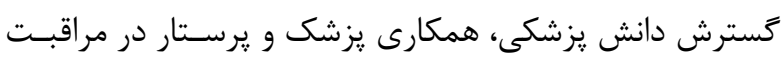

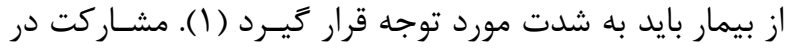

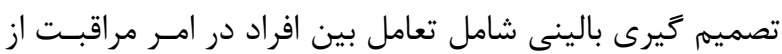

آدرس نويسنده مسئول: تهران، دانشگاه آزاد اسلامى، واحد علوم يزشكى تهران، شهلا محمد زاده زرنكشش : زئس (email: shmohammadzadeh@yahoo.com) ORCID ID: 0000-0002-2383-218x تاريخ دريافت مقاله: 9V/N/I

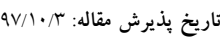


بستر بودند. در مقابل، برداشـت يزشـكان از يرسـتاران افـرادى

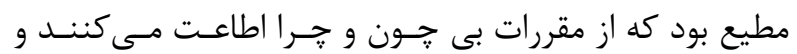
نخستين وظيفه آنها اجراى دستورات يزشكى و و تامين نيازهاى

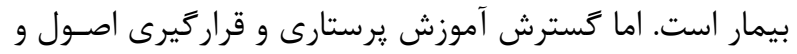

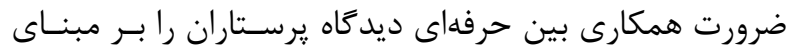

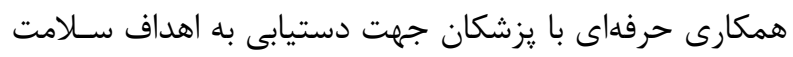
و با احترام به اصول حرفهاى يكسيخر تغييـر داده اسـت (11).

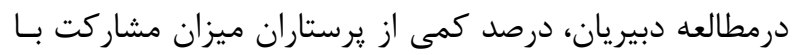

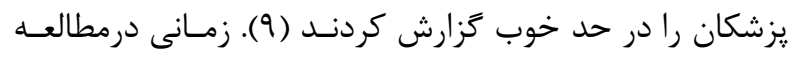

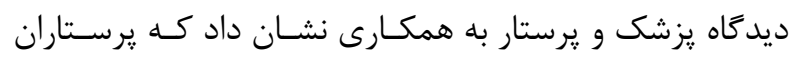
ديدكاه مثبت ترى به مشاركت داشتند (r) (I). برخى ازمطالعـات

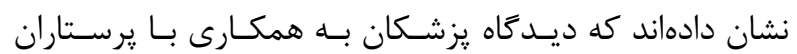

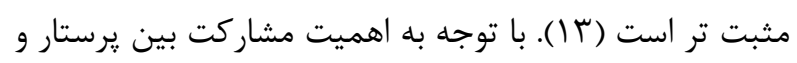

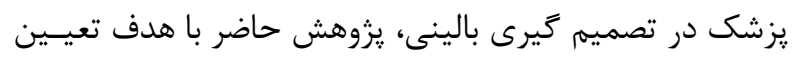

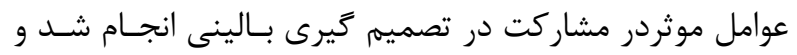

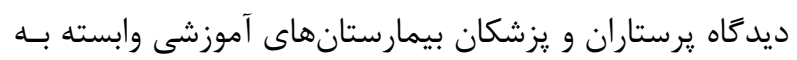

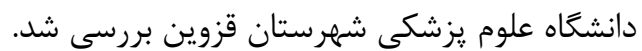

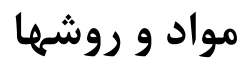

تحقيق توصيفى - تحليلى حاضر به صورت مقطعى بـا هـدف

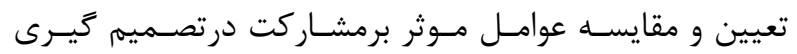

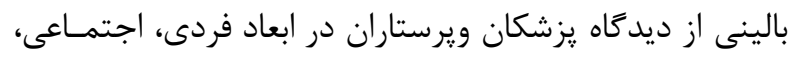

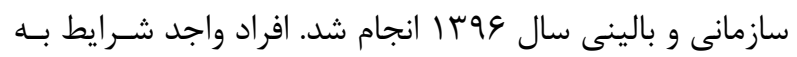

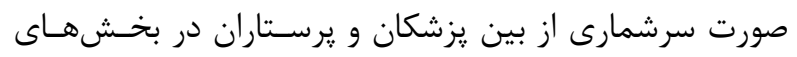

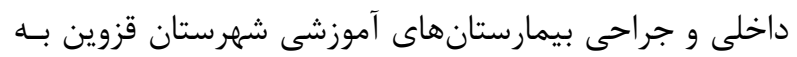

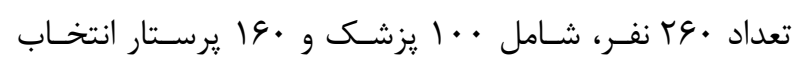

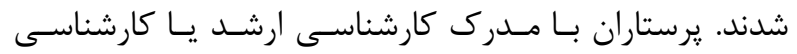

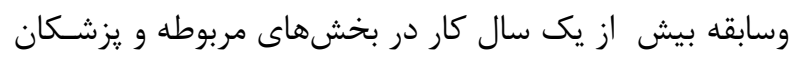

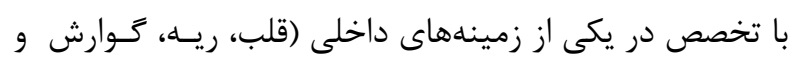

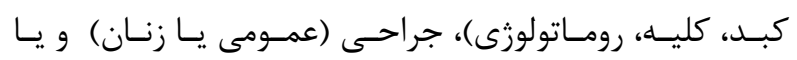
رزيدنت سال آخر در تخصصهاى مربوطه و سابقه كار بيشـتر

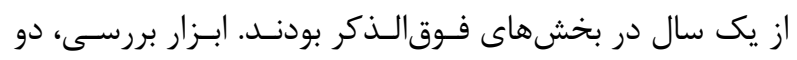

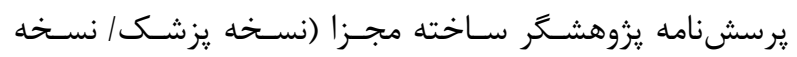

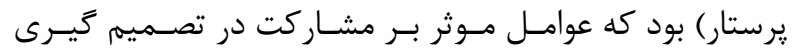

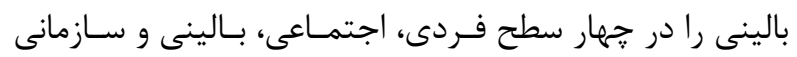

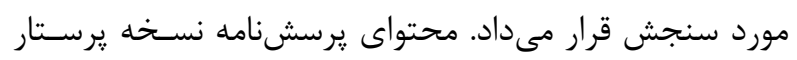

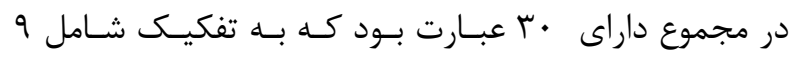

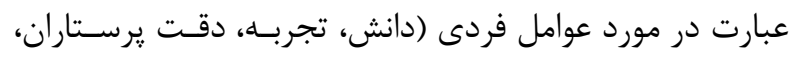

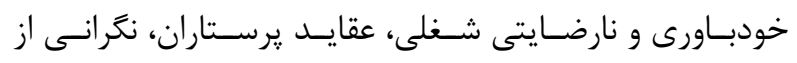

يرستار بسيار جدى است. اين عواقب شامل عدم همـاهنكى در

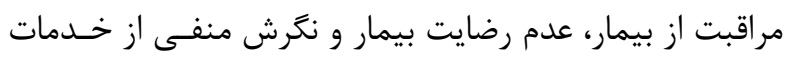

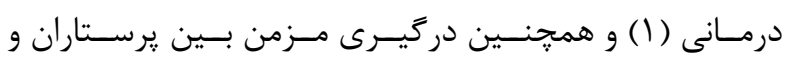

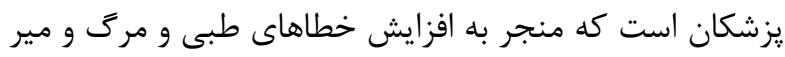

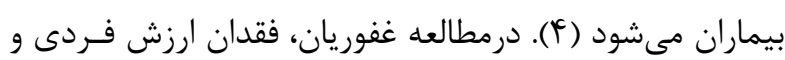

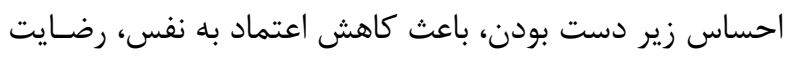

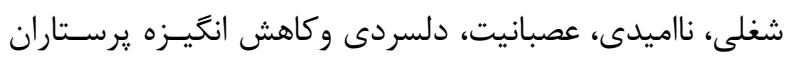

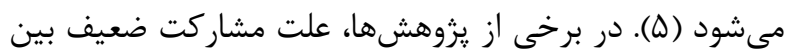

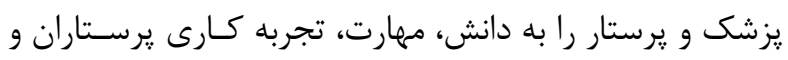

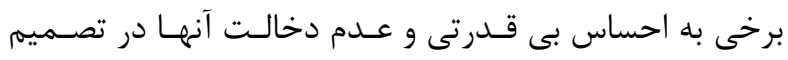

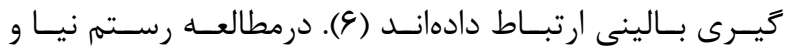

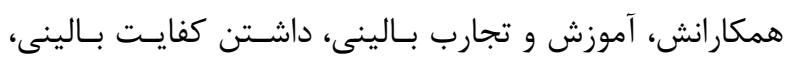

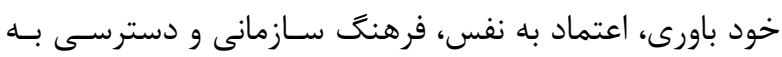

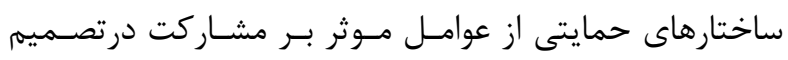

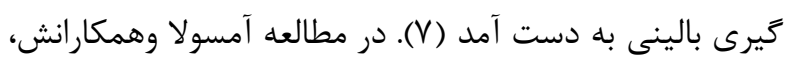

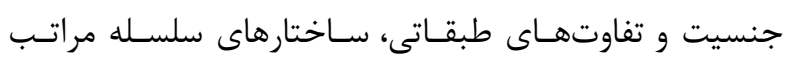

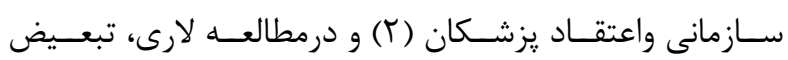

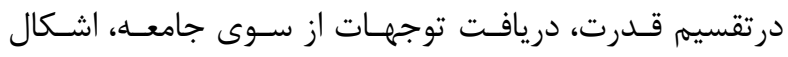

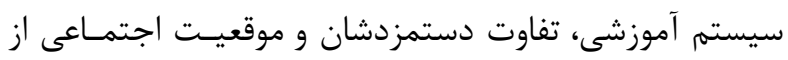

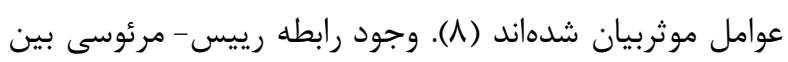

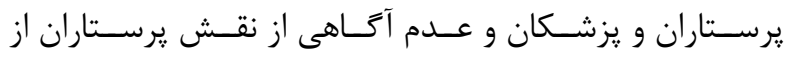

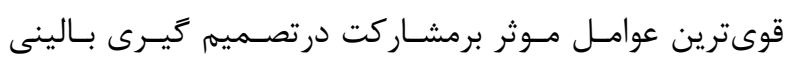

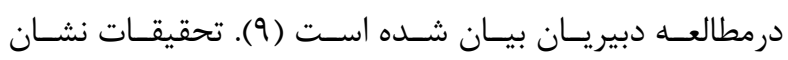
مى دهند كه در محيط هاى حرفهاى براى تصميمكيرى بـ بـالينى

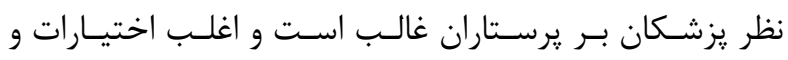

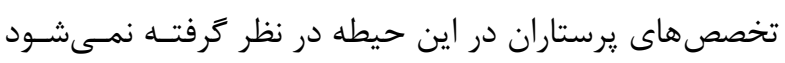

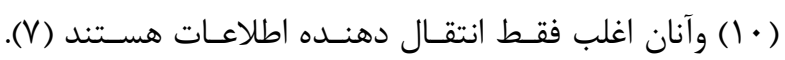

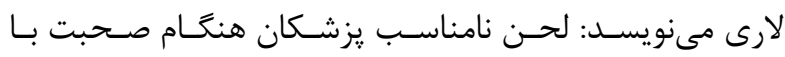

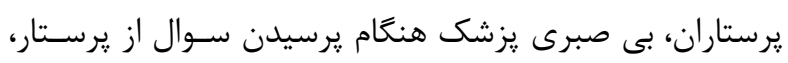

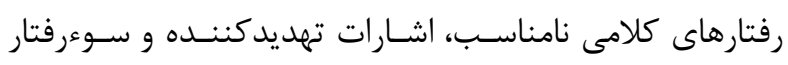

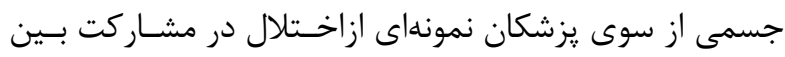

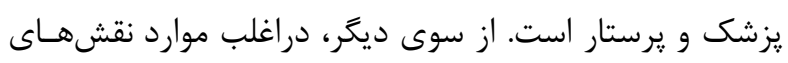

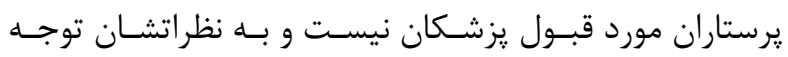

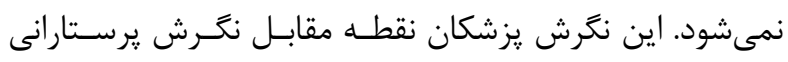

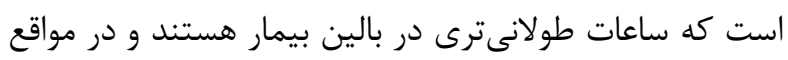

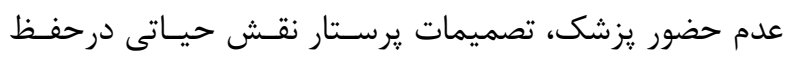

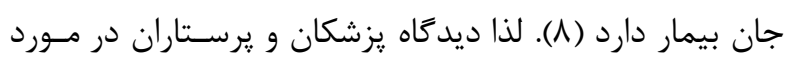

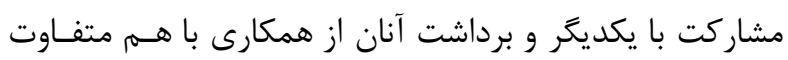

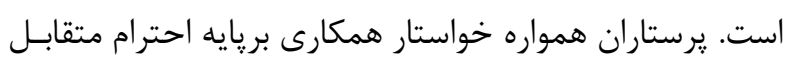

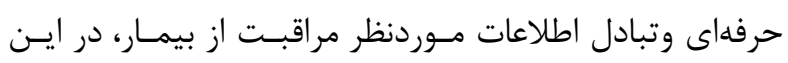


استفاده شد، به اين ترتيب كه برسشنامه بـه • •ا يزشـك و.1

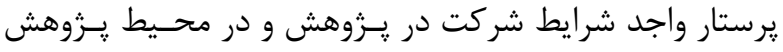

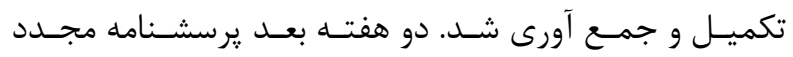

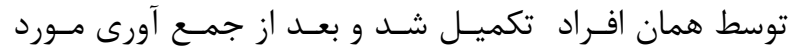

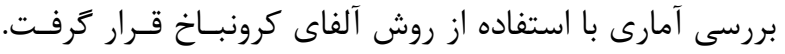

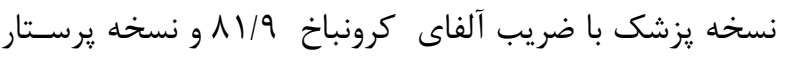

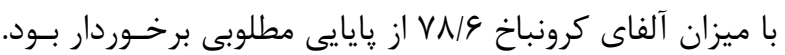
يس از تصويب يرويوزال يزوهش و ورعايت ملاحظـات اخلاقى لإنى

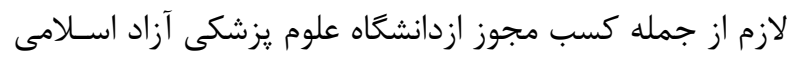

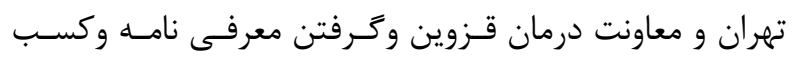

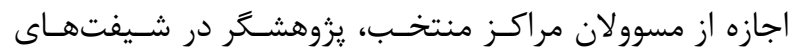

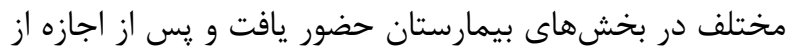

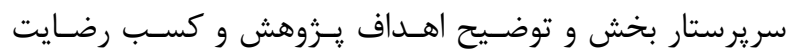

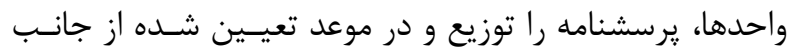
آنها جمع آورى كرد و با نرمافزار SPSS تحليل آمارى انجام شد.

\section{يافتهها}

در مطالعه حاضر، بيشتر يزشكان و يرستاران در سنين اب تا

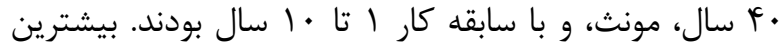

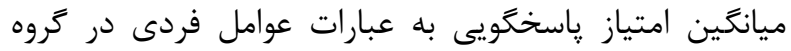
يزشكان مربوط به عبارت "يزشكان در رابطه با مورد مشورت قرار دادن يرستاران با هم عقيده يكسانى ندارند" بان بان ميانكَين

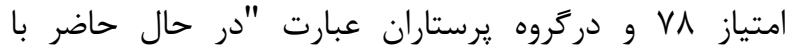

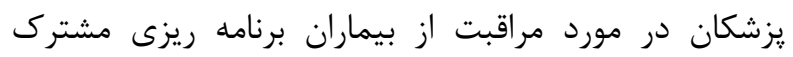

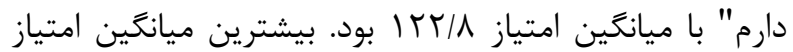

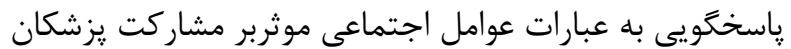

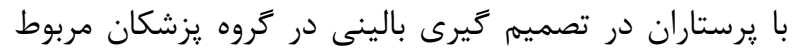

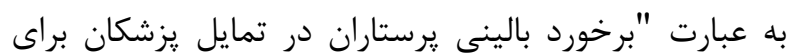

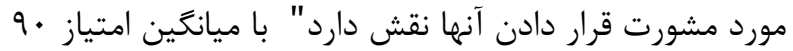
و در كروه يرستاران مربوط به عبارت "يزشكان ترجيح

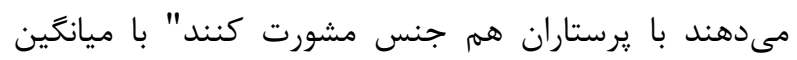

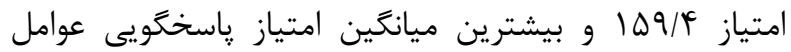
سازمانى در كروه يزشكان مربوط به عبارت "به كاركيرى شيوه

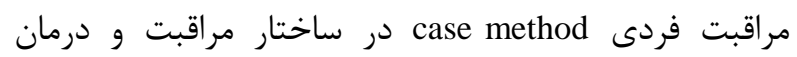
زمينه مشاركت در تصميم گيرى يزشكان را با يرستاران ايجاد

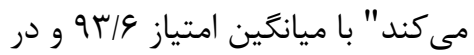

بازخورد رفتارى يزشكان)، V عبارت در مورد عوامـل اجتمـاعى

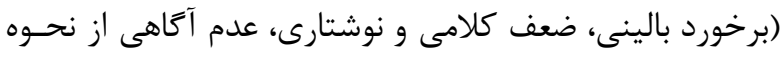

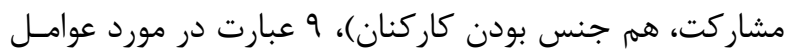

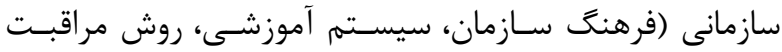

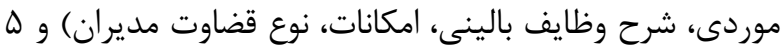

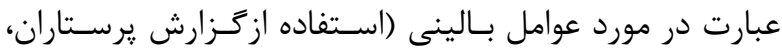
اشتراك مسوليت بالينى، جويايى نظر يرسـتاران) بـود. نسـخه

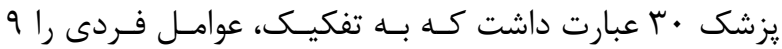

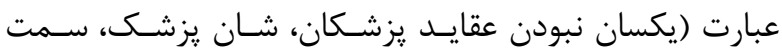

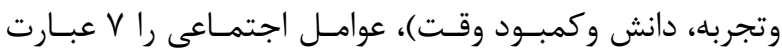

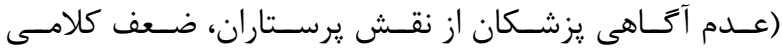

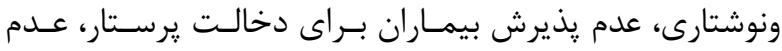

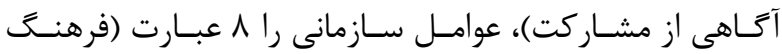

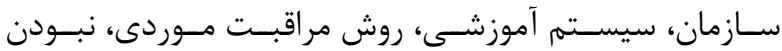

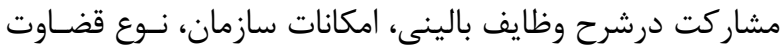

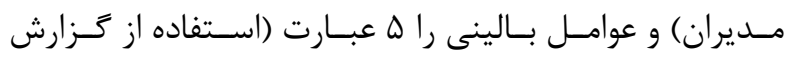

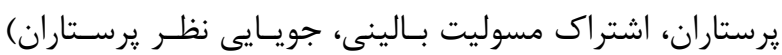

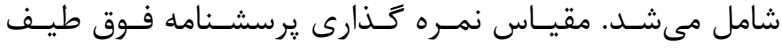

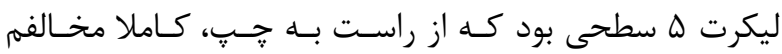

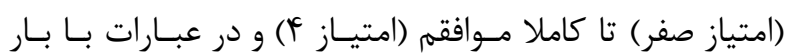

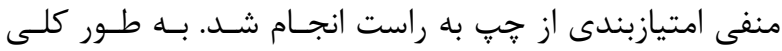

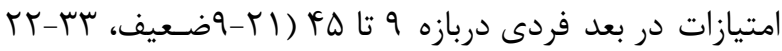

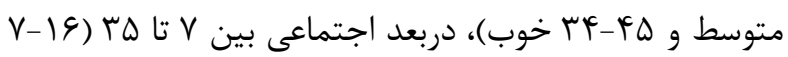

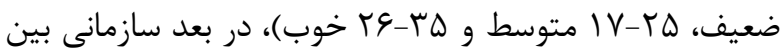

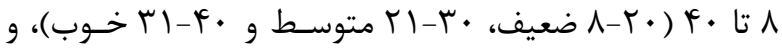

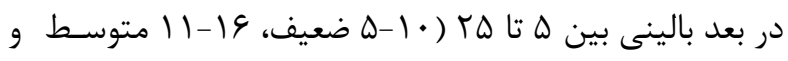

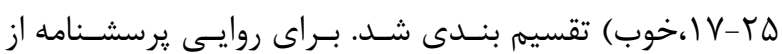

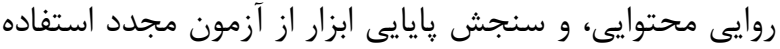

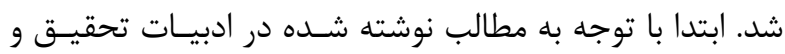

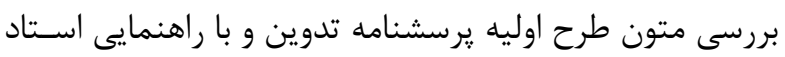

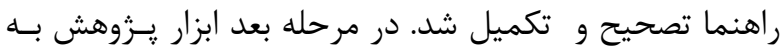
رويست هل نفــــ از اسـاتيد در دانشـكده برســارى دانشـعاه آزاد

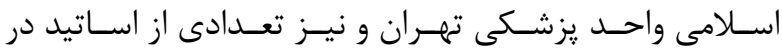

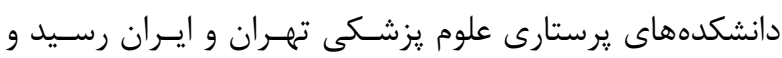

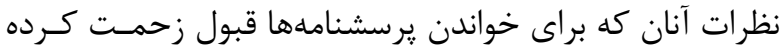

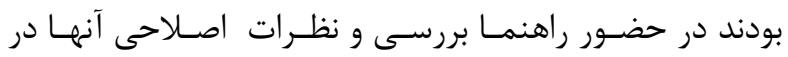

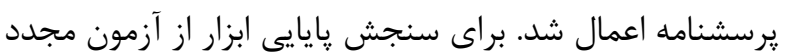




\begin{tabular}{|c|c|c|c|c|c|c|}
\hline ميانكين 土 انحراف & موافقم & 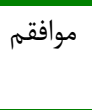 & 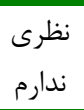 & 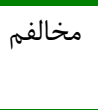 & مخالفم & شاخص عبارت يرسشنامه \\
\hline 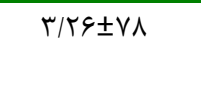 & $1 \cdots$ & TQ. & it & If & r & يزشكان 1 - يزشكان در رابطه با مورد مشورت قرار دادن يرستاران با هم \\
\hline$r / q| \pm r| / \Lambda$ & ru & 114 & · & rt & ra & r - يرستاران علم كافى براى مورد مشورت قرار كرفتن ندارند. \\
\hline$r / / \Delta \pm I r r / \Lambda$ & red & 191 & 10 & Qr & If & يرستاران اـ در حال حاضر با يزشكان در مورد مراقبت از بيماران برنامه ريزى \\
\hline$T / T \varphi \pm \Lambda V / / \varphi$ & $r$. & ve & $\Delta V$ & Ira & 14 & r ـ نارضايتى شغلى مانع از مشاركت فعال در مراقبت مى شود. \\
\hline$r / \cdots \pm q$ & rid & 114 & 10 & $\wedge$ & · & ماعى يزشكان 1 ـ برخورد بالينى يرستاران در مشاركت نقش دارند. \\
\hline$r / 11 \pm r \varepsilon / 9$ & rی & 1.9 & · & TY & 10 & r ـ يزشكان از نقشهاى تِرستاران در مراقبت و درمان اطلاعى ندارند. \\
\hline$r / 11 \pm 1 \Delta q / 4$ & 10 & $\Delta T$ & Tr. & rG. & r. & 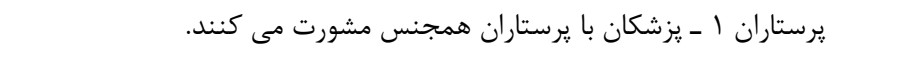 \\
\hline$r / T \Psi \pm \varepsilon \Delta / \Lambda$ & TH & १९ & 10 & $\wedge f$ & 4. & نكن - يزشكان هر تصميمى مى گيرند و ترجيح مى دهند دخالتى \\
\hline$r / 99 \pm 9 r / 9$ & rid & $1 K \Lambda$ & \& & 11 & $\Delta$ & مانى يزشكان ـ شيوه ى مراقبت موردى زمينه مشاركت را فراهم ميكنند. \\
\hline$r / \Lambda \Lambda \pm r \digamma F$ & 1. & rT & 9 & v. & kq & r ـ در سيستم موجود مشورت يرستاران عرف نيست. \\
\hline$r / V \Psi \pm I r$. & $r \cdot \Delta$ & trt & re & $\Delta F$ & rt & يرستاران 1 ـ سيستم آموزشى مراقبت تيمى را نمى آموزد. \\
\hline$\Gamma / \Lambda \Lambda \pm \Delta \Lambda / \varphi$ & $\Lambda \Delta$ & ir & r & 111 & is & r ـ شيوه ى مراقبت موردى زمينه ى مشاركت را فراهم مى كند. \\
\hline$r / l \varphi \pm V V / \varphi$ & $1 \wedge$ & 191 & 4 & rᄉ & 4 & 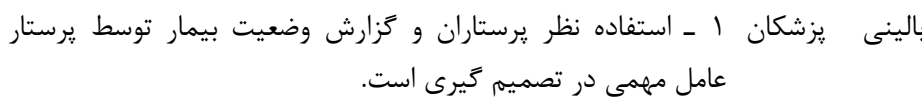 \\
\hline$r / r \Delta \pm \varepsilon \Lambda / \varphi$ & 11. & $1 \wedge$ & - & r. & ir & r ـ بهتر است يزشكان ، يرستاران با هم تصميم گيرى كنند. \\
\hline r/rm & $r \cdot \Delta$ & $1 M$ & rV. & \&A & 19 & يرستاران 1 ـ مسووليت هاى تصميم گيرى در مورد بيماران به اشتراى كذاشته \\
\hline $4 / r r \pm 1 \cdot 1$ & $1 \wedge$. & tre & re & v. & \} $&{\text { 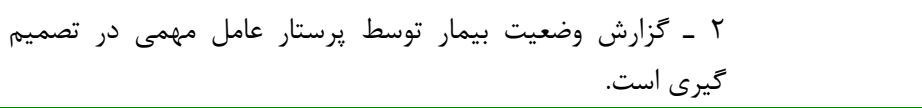 }} \\
$\hline
\end{tabular}

مستقل نشان داد كه يزشكان به عوامل اجتماعى، بالينى و

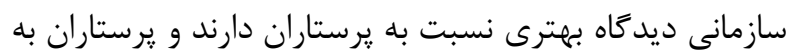

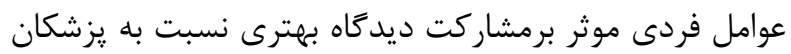

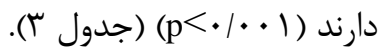
بررسى: ارتباط بين برخى متغيرهاى دموگرافيك با عوامل

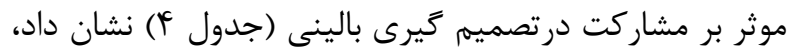
بين همه عوامل موثر بر مشاركت در تصميم گيرى بالينى، سن

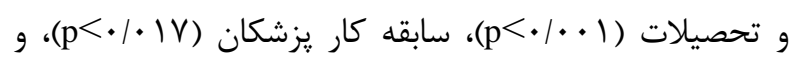

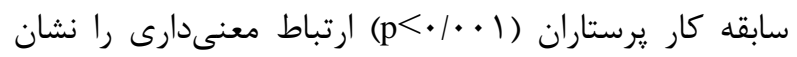

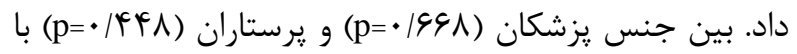

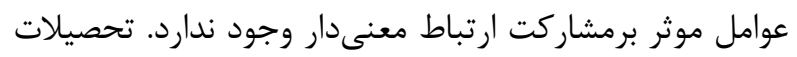
״رستاران تنها با عامل سازمانى ارتباطى نداشت وبا بقيه عوامل

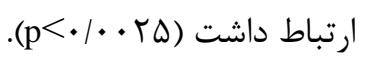

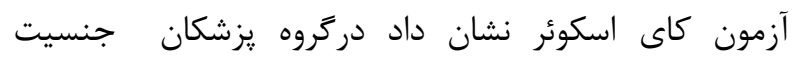

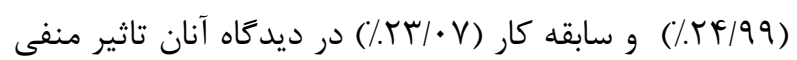

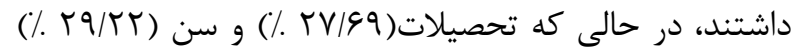

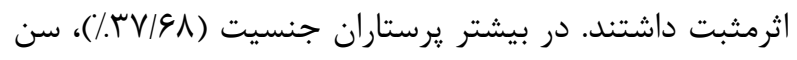

كروه ״رستاران مربوط به عبارت "سيستم آموزشى موجود،

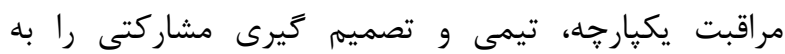

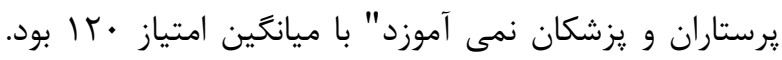

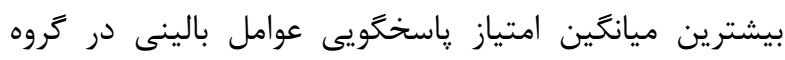

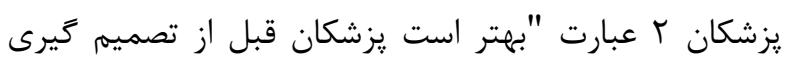
براى بيماران نظر يرستاران را در مورد بيمار جويا شوند" و و

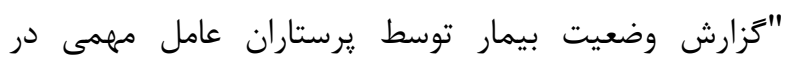

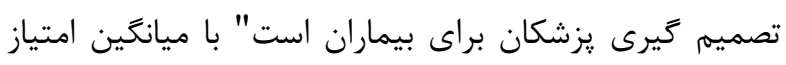
VV/G

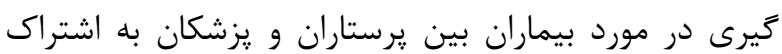

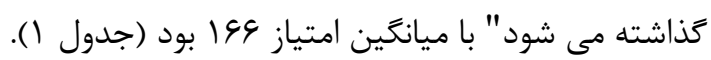

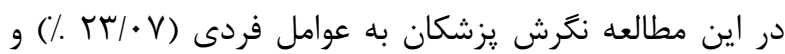

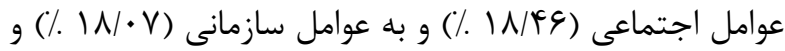

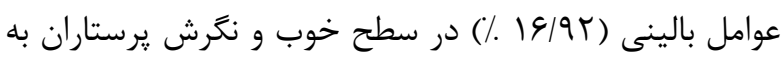

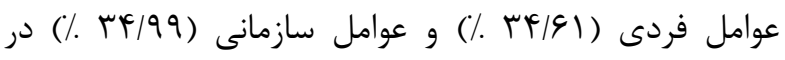

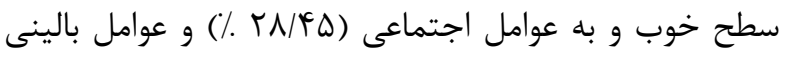

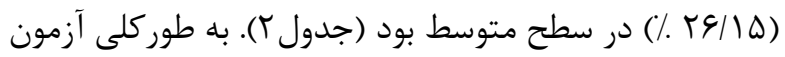


جدول r. فراوانى و درصد سطح ديدگاه يزشكان و يرستاران به عوامل موثر بر مشاركت درتصميم گيرى بالينى

\begin{tabular}{|c|c|c|c|c|}
\hline فراوانى(درصد) & فراوانى(درصد) & فراوانى(درصد) & دامنه نمرات & متغير \\
\hline$(\boldsymbol{F} \mathcal{F}-\mathcal{F} \Delta)$ & $(Y r-r M)$ & $(9-Y))$ & $q-F \Delta$ & عوامل فردى \\
\hline$(Y r / \cdot V) q$. & (N/Ar)Yr & $(\varphi / \Delta r) \mid V$ & & يز يزكان \\
\hline$(M Y / G \mid) q$. & $(19 / \mid Q) F r$ & $(1 \cdot / V \varepsilon) Y \Lambda$ & & يرستاران \\
\hline$(r \varepsilon-r \Delta)$ & $(I V-r \Delta)$ & $(V-19)$ & $v-r \Delta$ & عوامل اجتماعى \\
\hline$(\mid \Lambda / \Lambda \varepsilon) \& \Lambda$ & $(1 \Delta / V \varphi) F^{F}$ & $(F / K r) \| 1$ & & يزشكان \\
\hline$(Y \cdot / V \varphi) \Delta F$ & $(Y N / F \Delta) V F$ & Tr/T/RT & & يرستاران \\
\hline$(\boldsymbol{r} \mid-\boldsymbol{r} \cdot)$ & $(r \mid-r \cdot)$ & $\left(\Lambda-r_{+}\right)$ & $\Lambda-F$. & عوامل سازمانى \\
\hline$(\mid N / \cdot V) F V$ & (IT/4G) & $(9 / 9 Y) \backslash \Lambda$ & & يزشكان \\
\hline$(r F / 99) q 1$ & $(\mid V / q \Lambda) \& G$ & س & & يرستاران \\
\hline$(I V-r \Delta)$ & $(11-19)$ & $(\Delta-1 \cdot)$ & $\Delta-r \Delta$ & عوامل بالينى \\
\hline$(19 / 9 T) F F$ & $(I F / T H) r V$ & $(V / r \cdot) 19$ & & يزشكان \\
\hline$(Y F / T Y) G T$ & $(\Gamma \varphi / \backslash \Delta) \& \wedge$ & $(11 / / \Delta) r q$ & & يرستاران \\
\hline
\end{tabular}

جدول س. مقايسه و ميانگين امتياز ديدگاه يزشكان و يرستاران به عوامل موثر بر مشاركت در تصميم گيرى بالينى

\begin{tabular}{|c|c|c|c|c|}
\hline $\mathrm{P}$ & $\mathrm{T}$ & ميانكين |انحراف معيار يرستاران & ميانَين++انحراف معيار يزشكان & حيطه \\
\hline$\cdot 1 \cdot \cdot 1$ & $-F / \cdot \varphi_{1}$ & $1 \cdot / \cdot 1 \pm 10 V / 99$ & $9 / 9| \pm| 0 \cdot|9|$ & عوامل فردى \\
\hline$\cdot 1 \cdot \cdot 1$ & $-r / 9 \cdot \Delta$ & ৭/IV $\pm \vee V / \Lambda$. & $1 \cdot / r \varepsilon \pm \vee q / 4 \mu$ & عوامل اجتماعى \\
\hline$\cdot 1 \cdot \cdot 1$ & $-1 / 4 \mid \Delta$ & $|\varphi /| V \pm V V / \Lambda$. & $\mid \Delta / r \varepsilon \pm 1 \cdot 1 / r$ & عوامل سازمانى \\
\hline$\cdot 1 \cdot \Delta$ & $-4 / .99$ & $\Lambda / \backslash \Lambda \pm \mid q \vee / \Lambda)$ & $q / r| \pm r| \cdot|r|$ & عوامل بالينى \\
\hline
\end{tabular}

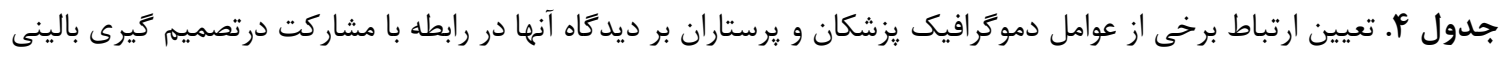

\begin{tabular}{|c|c|c|c|c|c|}
\hline p-value & كاى اسكوئر & فراوانى (درصد) پرستاران & فراوانى (درصد) يزشكان & 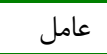 & متغير \\
\hline \multirow[t]{2}{*}{$<\cdot|\cdot \cdot|$} & FY/G\&V & $9 \wedge(r \vee / G \Lambda)$ & $9 D(T Y / 99)$ & اثرمنفى & جنس \\
\hline & rq/VT & GY(TM/AY) & $r \Delta(\mid r / \varphi s$ & اثرمثبت & \\
\hline \multirow[t]{2}{*}{$\cdot 1 \cdot \cdot 1$} & $11 / V \varepsilon$. & $\Lambda \varphi(Y \Psi / \vee V)$ & $T F(Q / T H)$ & اثرمنفى & سن \\
\hline & $\mid r / \Lambda \Delta$ & $V F(Y N / F \Delta)$ & $V G(Y q / T r)$ & اثرمثبت & \\
\hline \multirow[t]{2}{*}{$\cdot / \cdot \cdot \Delta$} & $41 \cdots$ & $1 \cdot r(r q / r T)$ & $r \wedge(1 \cdot / \vee \varepsilon)$ & اثرمنفى & تحصيلات \\
\hline & $\varphi / \ldots$ & $\Delta \Lambda(T r / T \cdot)$ & $V Y(Y V / G q)$ & اثرمثبت & \\
\hline \multirow[t]{2}{*}{$<\cdot / \cdot \cdot \cdot 1$} & $\varepsilon 9 / \mu \varepsilon$. & $r \cdot(11 / \Delta r)$ & $\varepsilon \cdot(Y r / \cdot V)$ & اثرمنفى & سابقه \\
\hline & GV/TF. & $1 \% \cdot(4 q / 9 q)$ & $F \cdot(\mid \Delta / r \Lambda)$ & اثرمثبت & \\
\hline
\end{tabular}

به عبارات عوامل فردى در گروه يزشكان مربوط به عبارت

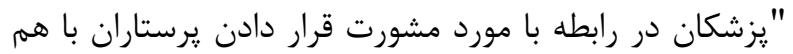

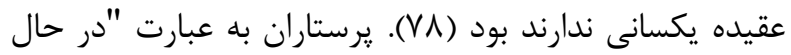

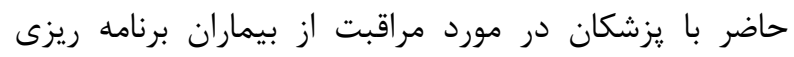

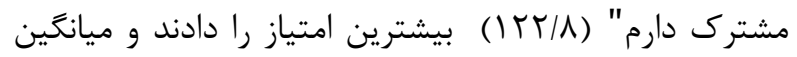

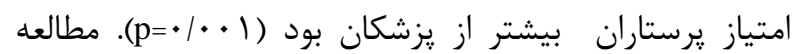

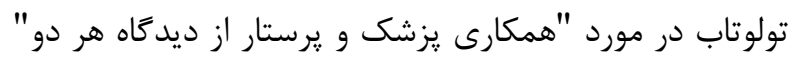

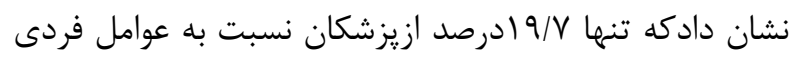
مشاركت ديد

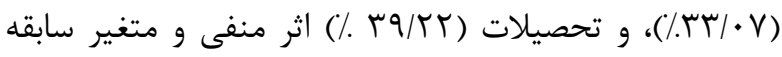

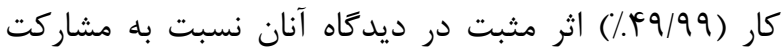

$$
\text { درتصميم گيرى بالينى داشت (جدول ؟). }
$$

در حالى كه ديد

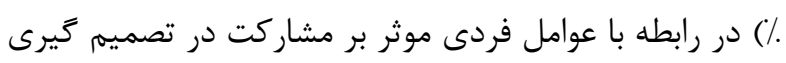

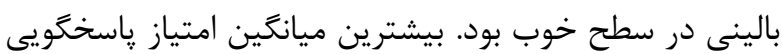


آموزشى موجود، مراقبت يكيارجه، تيمى و تصميم كيرى

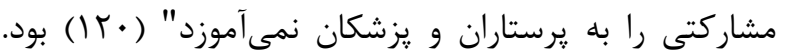

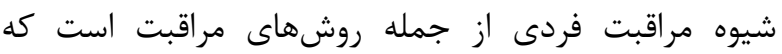

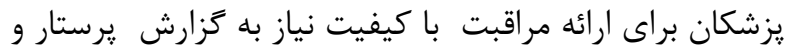

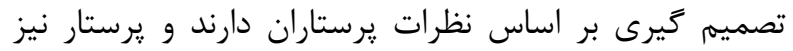

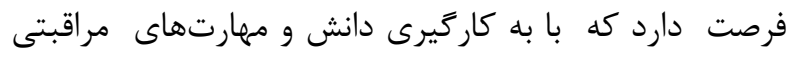
كيفيت كار خود را به نمايش بحذارد و زمينه مناسب مورد دارد مشورت قرار كرفتن را فراهم آورد. لذا يزشكان شيوه مراقبت فردى را عامل مهمى در تصميم كيرى مشاركتى عنوان كردند

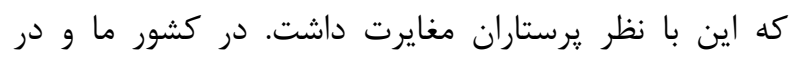

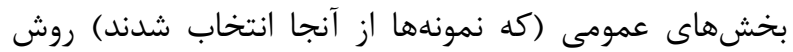

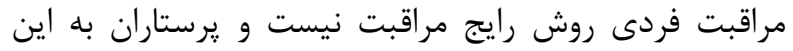

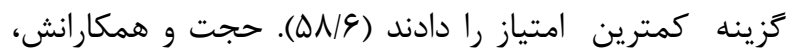
جهت ارتقاى تصميم گيرى بالينى، سيستم آموزشى كارامد را رادئ

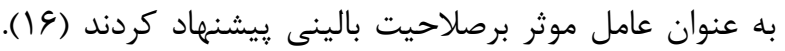

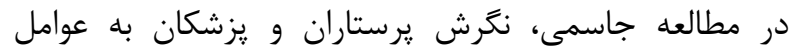

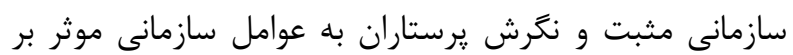

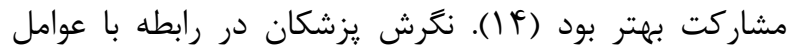
بالينى درسطح خوب قرار كرفت (19/9) (19). بيشترين ميانكين

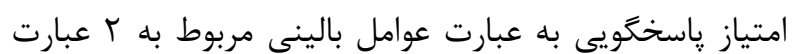

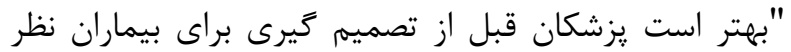

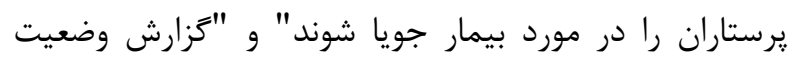

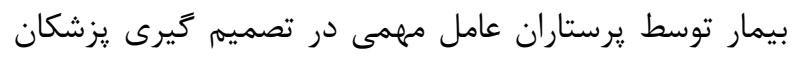

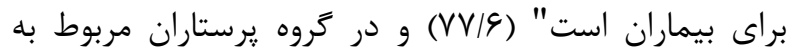
عبارت "مسئوليتهاى تصميم كيرى در مورد بيماران بين

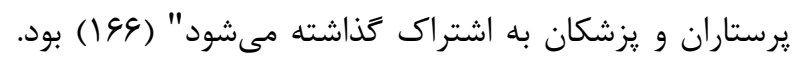
نكرش يرستاران در رابطه با عوامل بالينى در سطح متوسط

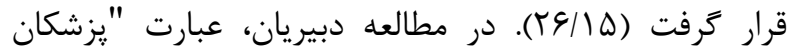
براى اطمينان از موثربودن برنامه درمانى خود اطلاعات مورد

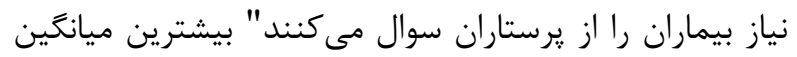

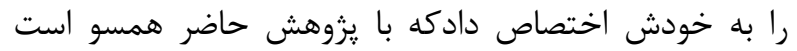

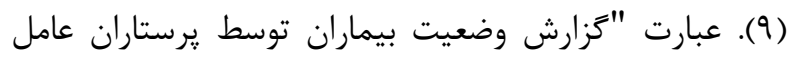

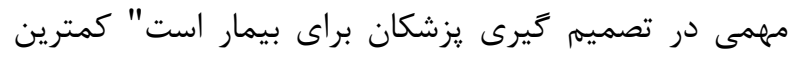

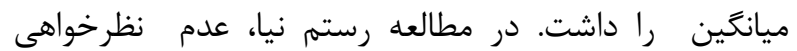

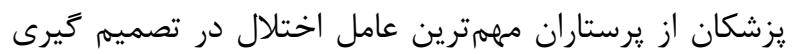

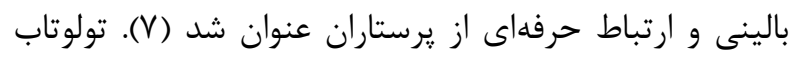

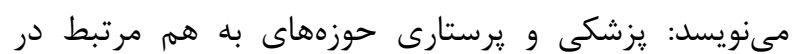

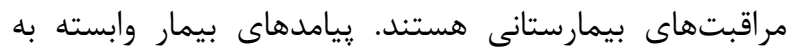
توانيى يزشكان در تشخيص و درمان، و مهارت يرستاران در بئمانيان

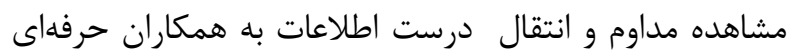

همخوانى ندارد. درمطالعه السوس مربوط به "نكرش يرستار و

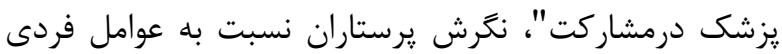
بالاتر و نكَرش يزشكان ضعيف بود (\&). درمطالعه دبيريان،

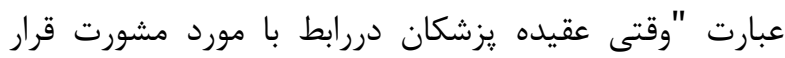
دادن يرستاران با هم يكى نيست، يرستاران به راحتى اظهار

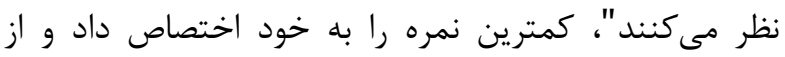
نكات منفى يزوهش بود كه با تحقيق حاظر همسو نيست (9). در مطالعه جاسمى و همكارانش، همكارى يزشك و يرستار

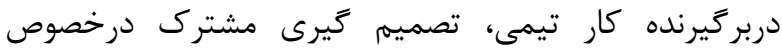
موضوعات سلامتى و دنبال كردن برنامه هاى مراقبتى بيمار

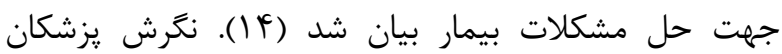
(IN/A9 ) در رابطه با عوامل اجتماعى موثر در سطح خوب قرار

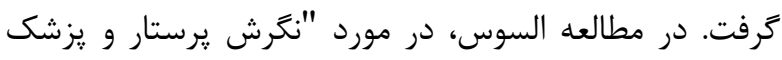
در مشاركت"، نكرش يزشكان به جنبه اجتماعى مشاركت ضعيف بود (\&). در اين تحقيق كمترين درصد يزشكان اعتقاد

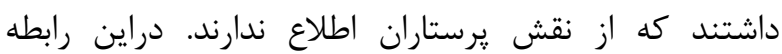

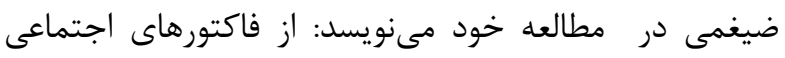
موثر در ارتباط كه بيشترين تاثير را درمشاركت دارد، كمبود آكاهى يزشكان نسبت به نقش يرستاران است (ها). لارى

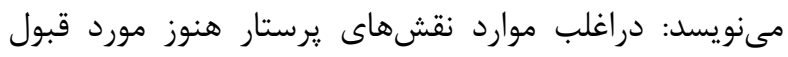
يزشكان نيست و :رستاران عضوى حاشيهاى وكم اهميت درنظر كرفته مىشوند و در تصميم كيرى به نظراتشان توجه

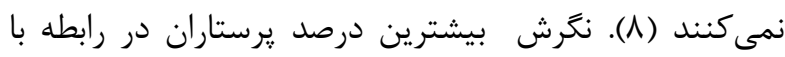

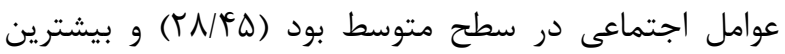

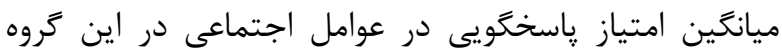
مربوط به عبارت "يزشكان ترجيح مىدهند با يرستاران هم إنمان

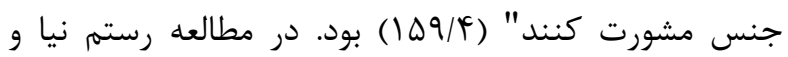
همكارانش يرستاران ترجيح كار با جنسيت همسان را مهرمترين عامل در نظر كرفتند (V). ميانگين امتياز يزشكان نسبت

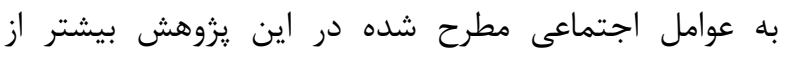

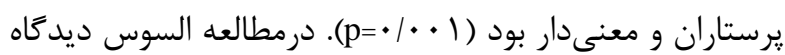
يرستاران به عوامل اجتماعى موثر بر مشاركت بهتر از يزشكان

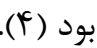
نكَرش هر دو كروه در رابطه با عوامل سازمانى موثر در

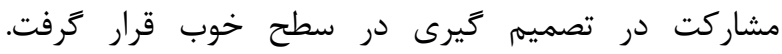

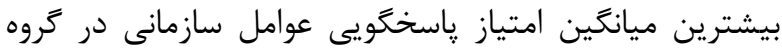

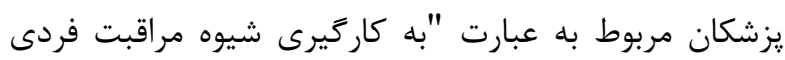

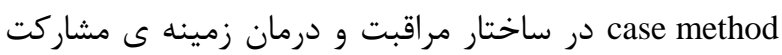

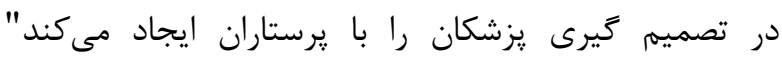

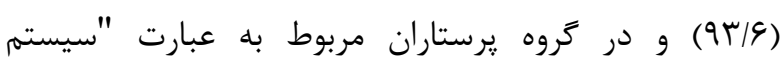


يرستاران، سيستم آموزشى موجود مراقبت يكيارجه را به به يه

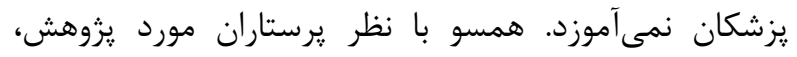

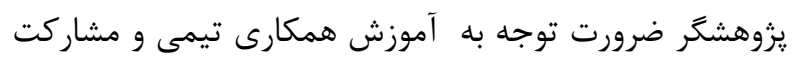

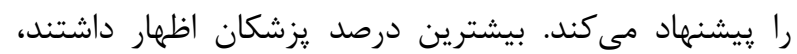

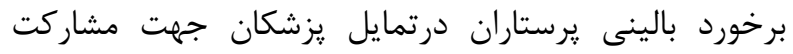

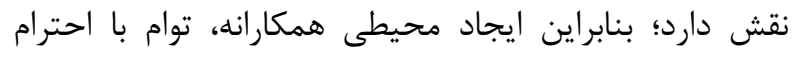

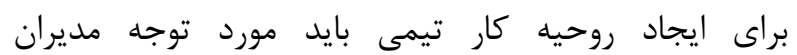
سيستمهاى بهداشت ودرمان قرار كيرد. از ديدكاه بيشتر يزشكان، شيوه مراقبت موردى روشى موثر براى ايجاد

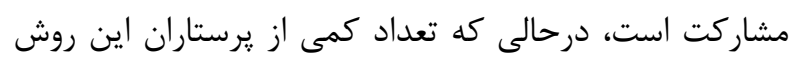
را موثر مىدانند. به نظر مىرسد كاركردن با روش مراقبت

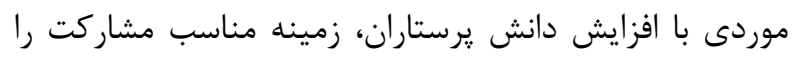

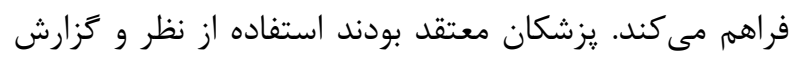
يرستاران در درمان و مراقبت بيماران موثر است. يرستاران

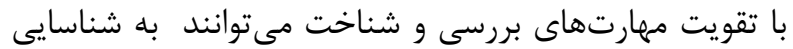

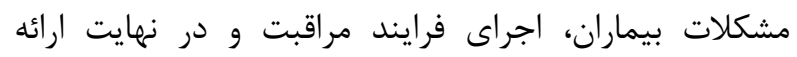

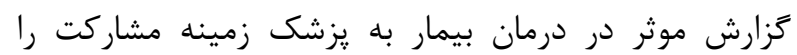

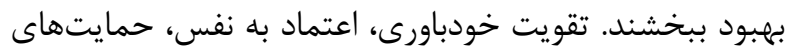
سازمانى نظير تشويق از طرف مديران يرستارى به مشاركت،

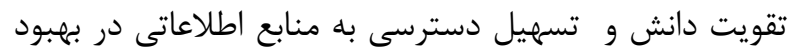
فرايند مشاركت حائز اهميت است. دانشكدهاى يرستارى ون و يزشكى، سازمانهاى حرفهاى، و مؤسسات استخدام كننده

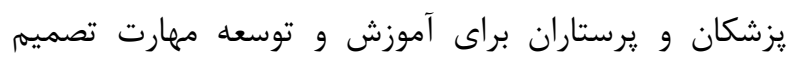
كيرى بالينى در يزشكان و يرستاران مسؤوليت مشترك دارند.

\section{قدردانى و تشكر}

در پايان از معاونت يزوهشى و آموزشى دانشكاه آزاد اسلامى ديى

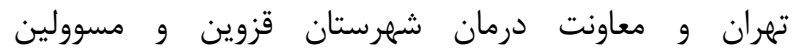

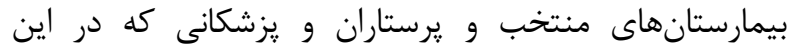

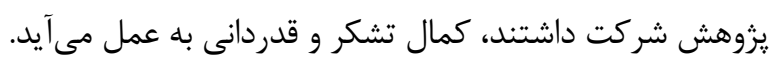

است. همكارى بى وقفه يزشك و يرستار براى دريافت و ارائه

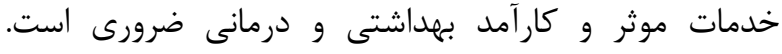
هرجند اين يك واقعيت است كه اين مساله اغلب وجود ندارد و تاثير منفى بر كيفيت خدمات مرقبتى و يزشكى مى خدارد (1). السوسدريزوهش خود نشان داد، هنوز مسووليتهاى تصميم كيرى بين يزشك و يرستار به اشتراك كذاشته

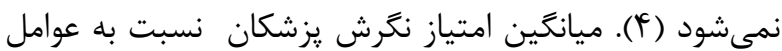

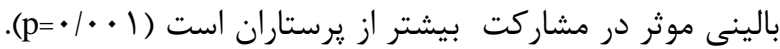
در كزارش تولوتاب و همكارانش و دبيريان و همكارانش، دان يرستاران نسبت به يزشكان در ارتباط با همكارى و مشاركت بالينى نكرش مثبت ترى داشتند (9، (1).

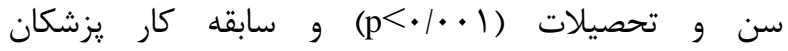

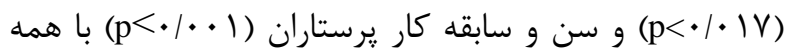
عوامل موثر بر مشاركت در تصميم گيرى بالينى ارتباط دارد.

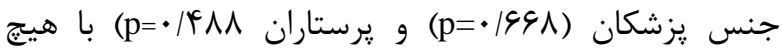

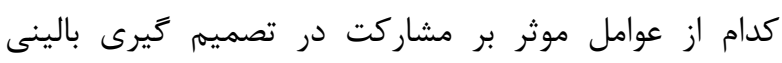

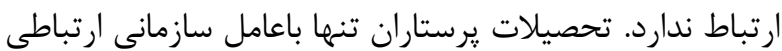

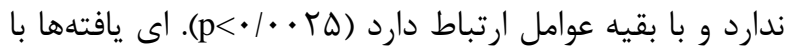

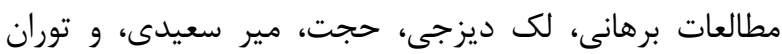

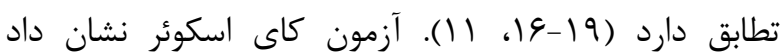

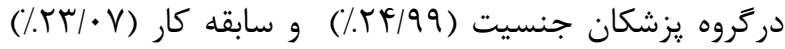

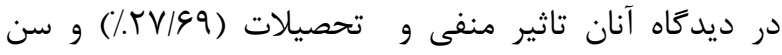

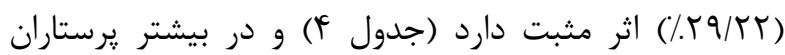
جنسيت (Y)

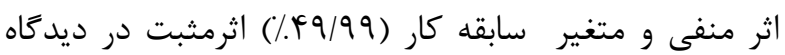

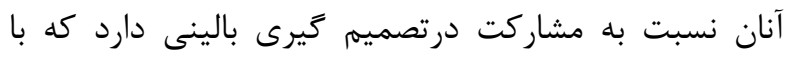
نتايج يزوهش رستمنيا و همكارانش و حجت مطابقت دارد باري

به طور كلى ديدكاه يزشكان نسبت به عوامل موثر بر مشاركت

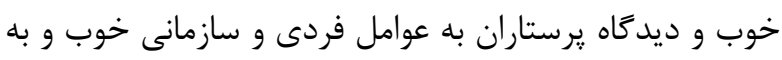
عوامل اجتماعى و بالينى متوسط بود. به اعتقاد تعداد زيادى از

\section{REFERENCES}

1. Tolutope FD, Olusegun AT, Ayodeji AM, Olayinka IS. Collaboration between doctors and nurses in a tertiary health facility in South West Nigeria: implication for effective healthcare delivery. International Journal of Caring Sciences. 2016;9:165-73.

2. Amsalu E, Boru B, Getahun F, Tulu B. Attitudes of nurses and physicians towards nurse-physician collaboration in northwest Ethiopia: a hospital based cross-sectional study. BMC Nurs 2014;13:37.

3. EL Sayed KA, Sleem WF. Nurse-physician collaboration: a comparative study of the attitudes of nurses and physicians at Mansoura university hospital. Life Sci J 2011; 8: 140-46.

4. Elsous A, Radwan M, Mohsen S. Nurses and physicians attitudes toward nurse-physician collaboration: a survey from Gaza Strip, Palestine. Nurs Res Pract 2017;2017:7406278 
5. Ghafourian Abadi S, Kamrani F. Critical care nurses' participation in clinical decision making with physicians Cardiovascular Nursing Journal. 2016;5:22-27. [In Persian]

6. Mosavi Nasab M, Shojaei Kh, Azodi P, Jahanpour F. Barriers and facilitators of clinical decision making among nurses. Quarterly Journal of Nursing Management. 2016;4: 45-52. [In Persian]

7. Rostamniya L, Ghanbari V, Kazemnejad Leili E. Factors associated with nurses' participation in clinical decision making. Iran Journal of Nursing. 2014;27:66-76. [In Persian]

8. Lari M, Ashghaly Farahani M, Jamshidiorak R, Bozorgnejad M. Survey of attitude of physicians and nurses toward physician-nurse collaborative relationships in general hospitals of Tehran University of Medical Sciences Iran. Journal of Nursing. 2013;8:58-64. [In Persian]

9.Dabirian A, Vaezi A, Ameri M, Kavousi A. Nurses' viewpoint about collaboration between physicians and nurses in clinical decision-making in the Hospitals of Tehran. Journal of Research Development in Nursing and Midwifery 2014;15:87-93. [In Persian]

10- Edwards PB, Rea JB, Oermann MH, Hegarty EJ, Prewitt JR, Rudd M, et al. Effect of peer-to-peer nurse-physician collaboration on attitudes toward the nurse-physician relationship. J Nurses Prof Dev 2017;33:13-18.

11. Borhani F, Abbasi M, Abbaszadeh A, Mousavi S. Attitudes of nurses and physicians of the hospitals affiliated with Shahid Beheshti University of Medical Sciences toward collaboration with each other. Medical Ethics and Law Research Center, Shahid Beheshti University of Medical Sciences, Tehran, Iran. IJME. 2018;7: 69-77. [In Persian]

12.Zamani AR, Zamani N, Sherafat Z. Assessment and compare of nurses and physicians views about doctor-nurse relationship cycle in Alzahra hospital. J Isfahan Med School. 2011; 28: 1529-36. [In Persian]

13. Maxson PM, Dozois EJ, Holubar SD, Wrobleski DM, Dube JA, Klipfel JM, et al. Enhancing nurse and physician collaboration in clinical decision making through high-fidelity interdisciplinary simulation training. Mayo Clin Proc. 2011;86:31-6

14. Jasemi M, Rahmani A, Aghakhani N, Hosseini FS, Eghtedar S. Nurses and physicians' viewpoint toward interprofessional collaboration. Iran Journal of Nursing 2013;26:1-10. [In Persian]

15. Zheygami SH, Haghighi S. Assessment of correlation between communication skills and communication and collaboration between nurses and physicians. Journal of Uremia Faculty of Nursing and Midwifery 2009;6:189-96. [In Persian]

16. Pakpour V, Hojat M, Salehi H, Rahmani A, ShahimA, Mohammadi R. Viewpoint of nurses on inter-professional relationship between nurses and doctors. Hayat, Journal of School of Nursing and Midwifery 2014;20:74-85. [In Persian]

17. Lak Diziji S. Nurses' participation in clinical decision-making process. J Nurs Midwifery Tabriz 2010;25:17-9. [In Persian]

18. Mirsaeedi GS, Ghoojazadeh M. Demographic factors involved in nurses' clinical decision making. Iran Journal of Nursing 2011;4:29-32. [In Persian]

19. Torunn B, Glenys A. Clinical decision making of nurses working in hospital setting. Nurs Res Pract 2011; 19:143165. 